\title{
CONSIDERAÇÕES SOBRE O PROGRAMA CONSTANTE DE INFORMAÇÕES DE DICIONÁRIOS ESCOLARES DE LÍNGUA PORTUGUESA VOLTADOS PARA O PÚBLICO INFANTIL
}

\author{
Larissa Moreira Brangel*
}

Resumo: $O$ presente trabalho tem por objetivo contrastar a constituição interna de verbetes de dicionários escolares Tipo 2 . A inclusão dos dicionários escolares de língua portuguesa ao Programa Nacional do Livro Didático ampliou as discussões sobre este tipo de obra lexicográfica, o que culminou em um aprimoramento dos dicionários escolares nos últimos dez anos. No entanto, por ser uma prática incipiente no Brasil, a pesquisa lexicográfica brasileira ainda carece de diretrizes que norteiem a compilação de dicionários escolares de excelência. Desta forma, embora compiladas sob diretrizes fixadas pelo Ministério da Educação, as obras disponíveis no mercado ainda apresentam características muito heterogêneas quando comparadas umas às outras. Neste trabalho, procuramos contrastar as informações oferecidas nos verbetes de três dicionários Tipo 2 de modo a chamar a atenção para a necessidade de um estudo que consolide um Programa Constante de Informações para estas obras lexicográficas.

Palavras-chave: Lexicografia Pedagógica; Dicionários Escolares; Programa Constante de Informações.

Abstract: This paper aims to contrast the internal formation of entries in Type- 2 school dictionaries. The inclusion of Portuguese school dictionaries in the Programa Nacional do Livro Didático

* Universidade Federal do Rio Grande do Sul. 
["Brazilian Textbook National Program"] has enhanced the discussions about this kind of dictionary, improving the compiling of school dictionaries in the last decade. However, lexicographical research in Brazil is still very incipient and it has not yet established guidelines that assure the compilation of high quality school dictionaries. Consequently, despite being compiled according to parameters fixed by the Ministry of Education, school dictionaries still present heterogeneous features when compared to each other. In this paper, we contrast the information presented by entries of three Type- 2 dictionaries, and we draw the attention to the need of a study that consolidates a Constant Program of Information to this sort of dictionary.

Keywords: Pedagogical Lexicography; School Dictionaries; Constant Information Program.

\section{Introdução}

Nos últimos dez anos, foi possível se observar um crescente interesse pela lexicografia pedagógica em solo brasileiro. Seja através de publicações de órgãos do governo dispostas a orientar o uso de dicionários em sala de aula (BRASIL, 2012), seja por meio de trabalhos acadêmicos dispostos a avaliarem e apresentarem propostas de aprimoramento para os dicionários pedagógicos (DAMIM, 2005; FARIAS, 2009; PIRES, 2012; SELISTRE, 2012), é evidente o esforço que tem sido feito para tornar os dicionários pedagógicos materiais didáticos cada vez mais funcionais.

Grande parte deste interesse advém da inclusão dos dicionários escolares de língua portuguesa ao Programa Nacional do Livro Didático (PNLD), ${ }^{1}$ fato ocorrido no ano de 2002. Antes da

\footnotetext{
${ }^{1}$ O Programa Nacional do Livro Didático (PNLD) é um programa desenvolvido pelo Ministério da Educação que visa a avaliar e distribuir livros (e, a partir de 2002, também dicionários de língua portuguesa) a serem utilizados em sala de aula no processo de ensino e de aprendizagem. Mais informações em: http:// portal. $\mathrm{mec}$.gov.br/index.php?Itemid $=668 \mathrm{id}=12391 \mathrm{option}=\mathrm{com}$ contentview $=$ article.
} 
inclusão dos dicionários ao referido programa, as obras lexicográficas utilizadas em sala de aula não eram necessariamente dicionários escolares, mas também dicionários do tipo mini ou conciso, por exemplo. Além disso, costumava-se empregar uma mesma obra lexicográfica durante todo o ensino básico, ignorandose o fato de que, com o avançar das etapas de aprendizagem linguística, o consulente apresenta diferentes necessidades de consulta. De acordo com Rangel (2011, p.39), a decisão política de avaliar dicionários de língua portuguesa utilizados na educação básica legitimou estas obras lexicográficas como um tipo específico de material escolar, conferindo-lhes um caráter de recurso didáticopedagógico fundamental.

Desta forma, nos anos subsequentes à primeira avaliação dos dicionários de língua portuguesa utilizados em sala de aula, o PNLD procurou apresentar uma nova proposta lexicográfica para este material didático que estabelecesse uma relação com as diferentes etapas do ensino fundamental, respeitando, assim, as demandas específicas de ensino e aprendizagem e, também, as práticas de letramento, alfabetização, leitura e escrita (RANGEL, 2011, p. 49). Por conseguinte, desde 2006, o PNLD tem apresentado sucessivos editais que buscam aprimorar os requisitos mínimos que um dicionário escolar deve cumprir para que seja avaliado. Abaixo, apresentamos as informações contidas no mais recente edital lançado pelo PNLD, do ano de 2012: 


\section{QUADRO 1}

Proposta lexicográfica para a compilação

de dicionários escolares - PNLD 2012

\begin{tabular}{|l|l|l|}
\hline $\begin{array}{l}\text { Tipos de } \\
\text { dicionários }\end{array}$ & Etapa de ensino & \multicolumn{1}{c|}{ Caracterização } \\
\hline Tipo 1 & $\begin{array}{l}1^{\circ} \text { ano do ensino } \\
\text { fundamental }\end{array}$ & $\begin{array}{l}\text { - Mínimo de } 500 \text { e máximo de 1.000 verbetes; } \\
\text { - Proposta lexicográfica adequada às demandas } \\
\text { do processo de alfabetização inicial. }\end{array}$ \\
\hline Tipo 2 & $\begin{array}{l}2^{\circ} \text { ao } 5^{\circ} \text { ano do } \\
\text { ensino fundamental }\end{array}$ & $\begin{array}{l}\text { - Mínimo de } 3.000 \text { e máximo de } 15.000 \text { verbetes; } \\
\text { - Proposta lexicográfica adequada a alunos em } \\
\text { fase de consolidação do domínio tanto da } \\
\text { escrita quanto da organização e da linguagem } \\
\text { típicas do gênero dicionário. }\end{array}$ \\
\hline Tipo 3 & $\begin{array}{l}6^{\circ} \text { ao } 9^{\circ} \text { ano do } \\
\text { ensino fundamental }\end{array}$ & $\begin{array}{l}\text { - Mínimo de } 19.000 \text { e máximo de 35.000 verbetes; } \\
\text { - Proposta lexicográfica orientada pelas } \\
\text { características de um dicionário padrão de uso } \\
\text { escolar, porém adequada a alunos dos últimos } \\
\text { anos do ensino fundamental. }\end{array}$ \\
\hline Tipo 4 & $\begin{array}{l}1^{\circ} \text { ao } 3^{\circ} \text { ano do } \\
\text { Ensino Médio }\end{array}$ & $\begin{array}{l}\text { - Mínimo de } 40.000 \text { e máximo de 100.000 verbetes; } \\
\text { - Proposta lexicográfica própria de um dicionário } \\
\text { padrão, porém adequada às demandas escolares } \\
\text { do ensino médio, nclusive o profissionalizante. }\end{array}$ \\
\hline
\end{tabular}

A inclusão dos dicionários escolares ao PNLD, bem como o sucessivo aprimoramento dos editais, revela uma evolução no quadro da lexicografia pedagógica brasileira, no sentido de assegurar a funcionalidade de obras lexicográficas escolares junto aos seus consulentes. Além disso, estes dois fatores indicam que há um reconhecimento, por parte dos órgãos governamentais, da importância do dicionário escolar como instrumento auxiliar ao ensino de português para falantes nativos em idade escolar.

Embora a criação do PNLD Dicionários tenha trazido contribuições para o uso de dicionários em sala de aula, é necessário lembrar que a lexicografia pedagógica ainda é uma prática incipiente no território brasileiro e, como tal, ainda carece

\footnotetext{
${ }^{2}$ Disponível em http://portal.mec.gov.br/index.php?option $=$ com_ content\& view $=$ article $\& i d=16841 \&$ Itemid $=1131$; acesso em 23/06/2013 .
} 
de estudos para ser aprimorada. Brangel e Bugueño Miranda (2012), por exemplo, demonstram que as definições lexicográficas de dicionários escolares aprovados pelo PNLD ainda apresentam problemas básicos de formulação. Antonioli (2011) demonstra que as exigências licitadas pelos órgãos governamentais sobre $o$ material léxico não asseguram a qualidade e a funcionalidade dos dicionários em sala de aula, pelo menos em relação aos dicionários voltados para as séries iniciais. Estes exemplos sevem para elucidar o estágio embrionário em que a compilação e os estudos sobre dicionários escolares se encontram.

Uma das consequências diretas da incipiência da pesquisa lexicográfica em solo brasileiro recai nos produtos finais da lexicografia pedagógica, ou seja, nos dicionários escolares comercializados para o uso em sala de aula. Tendo em vista a escassez de pesquisas conclusivas sobre como compilar bons dicionários escolares de língua portuguesa, o Ministério da Educação dispõe de uma base teórica ainda insuficiente na tarefa de formular parâmetros para o desenho e compilação de obras lexicográficas voltadas para o uso em sala de aula. Por conseguinte, as informações contidas nos próprios editais lançados pelo PNLD estão aquém de um conjunto de diretrizes minimamente satisfatórias para a compilação de obras lexicográficas de excelência.

Tomemos como exemplo as informações referentes ao dicionário Tipo 2 dispostas no mais recente edital lançado pelo PNLD (ver quadro 1). Embora o MEC se preocupe em fixar que o número de verbetes em um dicionário Tipo 2 deve oscilar entre 3.000 e 15.000 , pouco é dito a respeito de quais e quantos seriam estes verbetes, ${ }^{3}$ como eles estariam arranjados e como a sua constituição interna deveria estar organizada. Assim, ainda que as

\footnotetext{
${ }^{3}$ À discussão em torno do número e dos tipos de unidades a serem arrolados em uma obra lexicográfica subjaz a noção de macroestrutura quantitativa e macroestrutura qualitativa, respectivamente. Para estes conceitos, conferir Bugueño Miranda (2007a).
} 
editoras disponham de um pequeno manual na hora de compilar obras lexicográficas escolares de língua portuguesa, as orientações oferecidas por estas diretrizes são, ainda, muito vagas, fato que possibilita a compilação de obras lexicográficas com características um tanto distintas, embora direcionadas a um mesmo público-alvo.

Neste trabalho, procuraremos verificar a quantidade e o tipo de informação oferecida nos verbetes de três ${ }^{4}$ dicionários escolares voltados para o mesmo público (dicionário Tipo 2). Através da comparação dos verbetes, procuraremos demonstrar que algumas obras escolares de língua portuguesa, mesmo sendo compiladas segundo critérios estabelecidos pelo Ministério da Educação, ainda apresentam diferenças significativas na constituição dos seus verbetes. Neste sentido, procuraremos chamar a atenção para a necessidade de pesquisas lexicográficas que estabeleçam, com mais precisão e embasamento teórico, que tipo de informações seriam pertinentes em um verbete de dicionário Tipo 2 . Antes, no entanto, apresentaremos um pequeno panorama sobre o que a teoria lexicográfica tem postulado a respeito da constituição interna dos verbetes das obras lexicográficas.

\section{A megaestrutura de um dicionário semasiológico e o programa constante de informações}

Para compreendermos o lugar do programa constante de informações em uma obra lexicográfica, é necessário

\footnotetext{
${ }^{4} \mathrm{~A}$ escolha dos dicionários analisados ocorreu de maneira aleatória dentre as opções oferecidas pelo PNLD 2012. Na relação de obras Tipo 2 aprovadas pelo PNLD 2012, constam um total de sete obras lexicográficas. Tendo em vista que a análise das sete obras estenderia demasiadamente a discussão por ora proposta, optamos por restringir nossa análise a apenas três dicionários. A análise das três obras, ainda que moderada, não compromete o ponto central da discussão plantada, ou seja, a verificação de uma grande discrepância entre obras lexicográficas voltadas para um mesmo público-alvo.
} 
compreendermos, primeiramente, como esta obra lexicográfica se organiza. A megaestrutura de um dicionário semasiológico é constituída por uma série de componentes canônicos que, obedecendo a princípios organizacionais, garante que a obra lexicográfica seja, de fato, funcional (FARIAS, 2009, p. 57). Segundo a literatura especializada, os principais componentes que podem constituir a megaestrutura de um dicionário são a macroestrutura, a microestrutura, a medioestrutura e o outside matter (composto por front matter, middle matter e back matter) (HAUSMANN E WIEGAND, 1989; LANDAU, 2001; WELKER, 2004).

O outside matter (ou "textos externos", na terminologia de Welker (2004)) constitui todos aqueles elementos do dicionário que não correspondem à lista de palavras e suas definições. Algumas das informações trazidas pelo outside matter são: introdução, guia do usuário, figuras, lista de abreviaturas, regras de gramática, etc. Ao front matter correspondem todas as informações apresentadas antes da nomenclatura principal do dicionário (como a introdução e o prefácio, por exemplo). Ao middle matter correspondem as informações contidas dentro da macroescrutura do dicionário, mas que não fazem parte dos verbetes arrolados (como figuras e notas explicativas). Por fim, o back matter constitui o último componente do dicionário, trazendo informações que se situam após a nomenclatura principal do mesmo (como tabelas diversas e informações bibliográficas) (FARIAS, 2009, p. 248).

A macroestrutura, em uma visão bem geral, é definida como a lista ordenada das entradas, ou seja, a progressão vertical, geralmente disposta em ordem alfabética, que constitui o elemento central do dicionário (HARTMANN E JAMES, 2001; HAUSMANN \& WIEGAND, 1989; HAENSCH, 1982; WELKER, 2004). A medioestrutura, por sua vez, diz respeito ao sistema de remissivas que opera dentro da obra. Em outras palavras, trata-se de uma "rede de referências cruzadas que possibilita compiladores e usuários de uma obra de referência localizarem informações espalhadas por 
diversas partes integrantes da obra"5 (HARTMANN E JAMES, 2001, s.v. cross-reference structure).

O último componente canônico, e o que mais interessa aos propósitos do presente trabalho, diz respeito à microestrutura, ou seja, as informações que se encontram dentro do verbete. Hartmann e James (2001, s.v. microstructure), definem a microestrutura como "o desenho interno de uma unidade de referência", 6 e Hausmann e Wiegand (1989, p. 328) como "a estrutura de informações dentro do artigo lexicográfico". 7

A concepção de microestrutura apresentada por Hausmann e Wiegand (1989, p. 344) defende a necessidade de criação de uma base teórica que subjaza à microestrutura da obra lexicográfica. Segundo esta visão, os diferentes tipos de signo-lema ${ }^{8}$ devem obedecer a diferentes tipos de estruturação no artigo lexicográfico, contradizendo, assim, a concepção de artigos lexicográficos uniformes, ou seja, artigos que possuem a mesma estruturação, mesmo em se tratando de diferentes signos-lema. Esta base teórica responsável pela estruturação do verbete constitui o que Hausmann e Wiegand (1989) chamam de microestrutura abstrata, a saber, uma série de informações passíveis de constituírem o verbete que são estabelecidas de acordo com os tipos vocábulos a serem lematizados. Na prática, isto significa que "um dicionário geral de língua com $n$ tipos de signos-lema possui exatas $n$ microestruturas abstratas (hierárquicas)" ${ }^{\prime \prime}$ (HAUSMANN E WIEGAND, 1989, p. 344).

\footnotetext{
${ }^{5}$ No original: "The network of CROSS-REFERENCES which allows compilers and users of a reference work to locate material spread over different component parts".

${ }^{6}$ No original: "the internal design of a reference unit".

7 No original: "the structure of information within the article".

${ }^{8}$ Por signo-lema, entendemos os signos linguísticos arrolados pelo dicionário que cumprem o papel de palavra-entrada dos verbetes.

${ }^{9}$ No original: "a general monolingual dictionary with $n$ types of lemma signs has exactly $n$ abstract (hierarchical) microstructure".
} 
Juntamente com a noção de microestrutura abstrata se encontra a noção de microestrutura concreta, que é a representação direta da microestrutura abstrata na obra lexicográfica, ou seja, "a totalidade das informações linearmente ordenadas no interior de cada um dos verbetes" (FARIAS, 2009, p. 114). Podemos concluir, então, que, enquanto a microestrutura abstrata desenha o que seria a estrutura do verbete, a microestrutura concreta realiza esta estrutura, fazendo com que ela tome forma. Conforme aponta Farias (2009, p. 114), a microestrutura abstrata corresponde ao programa constante de informações de um dicionário (doravante PCI), que melhor detalharemos a partir de agora.

Em Fornari (2008, p. 10), o PCI é definido como "toda e qualquer informação que a microestrutura de um dicionário contenha e a sua disposição dentro do verbete". Para a autora, que se propõe a estudar of front matter de uma obra lexicográfica, quanto mais simples for o PCI de um dicionário, menos complexo será o processo de elaboração do front matter desta obra, tendo em vista que uma das funções básicas deste componente do dicionário é servir como um manual de instruções ao consulente (FORNARI, 2008, p. 5). Assim, tendo em vista que uma das funções do front matter é ajudar o consulente a compreender cada um dos segmentos informativos encontrados no verbete, quanto mais complexo for o PCI da obra, mais explicativo terá que ser o front matter desta mesma obra. Esta constatação nos leva a crer que o PCI pode estar também relacionado a outros componentes canônicos do dicionário.

Em relação aos constituintes que compõem um PCI, Bugueño Miranda (2007b, p. 120), ao analisar a microestrutura de um dicionário do alemão, apresenta as paráfrases explanatórias, as colocações, os compostos, a valência, a sinonímia, a antonímia e as expressões idiomáticas como segmentos pertencentes ao PCI deste dicionário, que, segundo o autor, "apresenta um programa relativamente ambicioso" (BUGUEÑO MIRANDA, 2007b, p. 120) em virtude da grande quantidade de informações oferecidas ao consulente, bem como o modo complexo que muitas destas informações são apresentadas. É necessário salientar, também, que 
tanto a presença quanto a ausência dos segmentos informativos da microestrutura possuem um valor dentro do verbete, pois, conforme aponta Damim (2005, p. 83-84), "um programa constante de informações implica um comprometimento com o nível zero de informação, que pode ser tão significativo quanto a presença de outras informações".

A noção de PCI apresentada até agora deixa transparecer a importância singular que este elemento ocupa nas obras lexicográficas. Em uma situação ideal (ou seja, em um verbete bem construído), as informações trazidas pelo PCI devem ser funcionais e estar organizadas de maneira estratégica, de modo a fazer do verbete um conjunto padronizado de informações no qual tanto a presença quanto a ausência de uma informação seja significativa e tenha sido planejada (BUGUEÑO MIRANDA, 2007a, p. 105-106). Levando a cabo estas considerações, procuraremos analisar, na seção seguinte, as informações apresentadas no PCI de três obras lexicográficas Tipo 2 , ou seja, dicionários escolares de língua portuguesa compilados para alunos do $2^{\circ}$ ao $5^{\circ}$ ano do ensino fundamental, conforme estabelecido pelo PNLD 2012 (conferir quadro 1).

\section{Análise do PCI de três dicionários escolares Tipo 2}

Nesta seção, procuraremos analisar a quantidade e o tipo

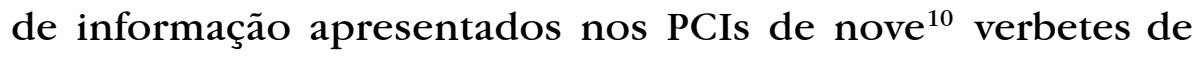

\footnotetext{
${ }^{10}$ Neste ponto do trabalho, é importante salientar que optamos por restringir a análise a apenas nove verbetes em função do aprofundamento da discussão proposta. Tendo em vista que o presente trabalho não se propõe a ser um estudo exaustivo, e sim uma avaliação inicial da configuração dos PCIs de dicionários Tipo 2, preferimos limitar a análise a poucos verbetes para podermos explorar cada um deles de maneira minuciosa. A apreciação de um número grande de verbetes acarretaria em análises mais rasas ou, em caso de análises minuciosas, em um trabalho deveras extenso, fugindo, assim, do propósito do presente artigo.
} 
dicionários Tipo 2 aprovados pelo PNLD 2012: AuIl (2008), DiJr (2005) e SaJr (2010). ${ }^{11}$ Para tanto, selecionamos três itens lexicais de categorias gramaticais distintas (um substantivo, um adjetivo e um verbo, escolhidos de maneira aleatória) e observamos as informações dispostas nos verbetes de AuIl (2008), DiJr (2005) e SaJr (2010) correspondentes a cada um dos itens lexicais. Para uma melhor visualização dos resultados, optamos por dispor as informações em quadros comparativos. Cabe, ainda, salientar que não procuramos avaliar a qualidade ou a pertinência das informações, visto que isto demandaria um trabalho bem mais longo que a proposta do presente artigo. Nosso objetivo, no momento, é apenas analisar a configuração do PCI de obras lexicográficas compiladas para o mesmo público-alvo e comparálas entre si. Abaixo, segue o resultado das análises.

QUADRO 2

Informaçóes encontradas nos verbetes do item lexical rapaz

\begin{tabular}{|l|c|c|c|}
\hline & AuIl (2008) & DiJr (2005) & SaJr (2010) \\
\hline Paráfrase explanatória & Sim & Sim & Sim \\
\hline Exemplo & Não & Não & Sim \\
\hline Classe gramatical & Sim & Sim & Sim \\
\hline Separação silábica & Sim & Sim & Sim \\
\hline Indicação da sílaba tônica & Sim & Não & Sim \\
\hline Aumentativo & Não & Sim & Sim \\
\hline Diminutivo & Não & Sim & Sim \\
\hline Coletivo & Não & Sim & Não \\
\hline Feminino & Não & Não & Sim \\
\hline
\end{tabular}

${ }^{11}$ A utilização de siglas para fazer referência a obras lexicográficas é uma prática bastante utilizada pelos teóricos da Metalexicografia. Optamos por seguir esta tendência ao longo de nossas considerações. 


$$
\text { QUADRO } 3
$$

Informações encontradas nos verbetes do item lexical ruim

\begin{tabular}{|l|c|c|c|}
\hline & AuIl (2008) & DiJr (2005) & SaJr (2010) \\
\hline Paráfrase explanatória & Sim & Sim & Sim \\
\hline Exemplo & Sim & Sim & Sim \\
\hline Classe gramatical & Sim & Sim & Sim \\
\hline Separação silábica & Sim & Sim & Sim \\
\hline Indicação da sílaba tônica & Sim & Não & Sim \\
\hline Indicação de pronúncia & Sim & Sim & Não \\
\hline Plural & Sim & Não & Não \\
\hline Remissão para outro verbete & Não & Sim & Não \\
\hline Antonímia & Não & Não & Sim \\
\hline
\end{tabular}

QUADRO 4

Informações encontradas nos verbetes do item lexical arrumar

\begin{tabular}{|l|c|c|c|}
\hline & AuIl (2008) & DiJr (2005) & SaJr (2010) \\
\hline Paráfrase explanatória & Sim & Sim & Sim \\
\hline Exemplo & Sim & Sim & Sim \\
\hline Classe gramatical & Sim & Sim & Sim \\
\hline Separação silábica & Sim & Sim & Sim \\
\hline Indicação da sílaba tônica & Sim & Não & Sim \\
\hline Remissão para outro verbete & Não & Sim & Não \\
\hline Remissão para uma gravura & Sim & Não & Não \\
\hline Antonímia & Não & Sim & Não \\
\hline
\end{tabular}

Os quadros 2, 3 e 4 demonstram que existe uma diferença significativa na quantidade e no tipo de informação fornecidos pelos PCIs de AuIl (2008), DiJr (2005) e SaJr (2010). Conforme é possível observar, os verbetes das três obras apresentam características bastante heterogêneas ao serem comparados entre si (nos verbetes correspondentes aos itens lexicais rapaz, ruim e arrumar). Em um total de 14 informações discriminadas, apenas três são apresentadas pelas três obras: a paráfrase explanatória, a classe gramatical e a separação silábica. Descartando estas três informações, restam, ainda, onze tipos de informações que são oferecidas por AuIl (2008), DiJr (2005) e SaJr (2010) sem que haja um consenso entre as obras sobre 
o tipo de informação apresentado. Será sobre estas informações que procuraremos tecer algumas considerações.

Para fins de organização, as informações foram separadas em grupos distintos, de acordo com a função que acreditamos que possam cumprir. No primeiro grupo, acomodamos informações que visam a auxiliar o consulente na compreensão do significado do item lexical (exemplos, remissão a outro verbete e remissão a uma gravura). No segundo grupo, reunimos as informações que parecem auxiliar a tarefa de produção textual dos consulentes (coletivo e antonímia). No terceiro e último grupo, discriminamos informações que fornecem ao consulente algum tipo de orientação sobre o uso da língua (aumentativo, diminutivo, feminino, indicação de pronúncia e plural).

A discussão sobre o primeiro grupo de informações (informações que auxiliam a compreensão do item lexical) pode ser conduzida com base no principal segmento informativo responsável pela elucidação do significado das palavras, a saber, a paráfrase explanatória (FARIAS, 2012). Para esta discussão, utilizaremos a proposta de Farias (2008) para a classificação de paráfrases explanatórias de acordo com a sua funcionalidade. Em sua proposta, a autora estabelece a existência de três tipos de paráfrases: as paráfrases explanatórias transparentes (paráfrases precisas, que cumprem a função de informar ao leitor o significado das palavras, logo, não necessitam ser complementadas) e paráfrases explanatórias do tipo opacas (paráfrases que não esclarecem ao leitor o significado das palavras) (FARIAS, 2008, p. 106). Ainda segundo a autora, as paráfrases opacas podem ser de dois tipos: paráfrases opacas deficitárias (quando a opacidade da paráfrase ocorre em virtude da má formulação da mesma) e paráfrases opacas propriamente ditas (quando a paráfrase define uma unidade léxica cuja dificuldade de definição é intrínseca a esta unidade léxica). Seguindo estes preceitos, a paráfrase opaca deficitária pode ser reformulada e convertida em uma paráfrase transparente, ao passo que apenas as paráfrases opacas propriamente ditas necessitariam ser complementadas por outros segmentos informativos, tais como exemplos e ilustrações. 
A proposta apresentada por Farias (2008), embora tenha como foco a discussão a respeito da utilização de exemplos, permite que a discussão também seja estendida ao âmbito das remissões. Desta forma, enxergar o exemplo, a remissão a outros verbetes ou a remissão a ilustrações como mecanismos restritos às paráfrases explanatórias opacas propriamente ditas auxiliaria os compiladores de dicionários a estabelecerem parâmetros sobre como e quando utilizarem estes mecanismos, de modo a os adotarem este mecanismo de maneira mais consensual (diferentemente do que é visto nos verbetes analisados). Para tanto, seria necessário um estudo aprofundado sobre a geração de paráfrases transparentes, bem como um estudo sobre a conversão de paráfrases opacas propriamente ditas em paráfrases transparentes. No caso da presente análise, caberia aos compiladores de AuIl (2008), DiJr (2005) e SaJr (2010) verificarem se as paráfrases explanatórias de rapaz, ruim e arrumar constituem paráfrases opacas propriamente ditas e se, por isso, necessitariam de complementos. Vejamos o exemplo das paráfrases relativas ao item rapaz em DiJr (2005) e SaJr (2010):

EXEMPLO 1: Verbete do item lexical rapaz em Dijr (2005)

rapaz sm. 1. Pessoa do sexo masculino entre os quinze e dezoito anos de idade: adolescente, jovem, moço. 2. Pessoa do sexo masculino entre os quinze e os dezoito anos e a idade de completo desenvolvimento: jovem, moço. Col.: rapaziada. Aum.: rapagão. Dim.: rapagote, rapazelho, rapazola, rapazote. Ra.paz.

EXEMPLO 2: Verbete do item lexical rapaz em SaJr (2010)

$\overline{\text { rapaz (ra.paz) sm Homem jovem ou adolescente; moço (o rapaz convidou a moça para }}$ ir à festa.). Fem. rapariga. Aum. rapagão. Dim irreg rapazelho e rapazote.

Conforme é possível observar, as paráfrases apresentadas por Dijr (2005) apresentam um potencial elucidativo satisfatório, ou seja, parecem descrever adequadamente o conteúdo semântico do item lexical rapaz. Por apresentarem um bom poder explanatório, é possível que classifiquemos as paráfrases de Dijr (2005) como paráfrases transparentes que, por cumprirem sua função de informar 
o consulente o significado do vocábulo arrolado, não necessitam de complementos para a explanação do significado (neste caso, o tratamento lexicográfico apresentado por DiJr (2005) nos parece adequado). A paráfrase fornecida por SaJr (2010), por outro lado, parece não ser tão satisfatória em relação ao poder explanatório, soando até mesmo um pouco confusa. Neste caso, somos levados a crer que se trata de uma paráfrase opaca deficitária, ou seja, uma paráfrase que pode ser convertida em uma paráfrase transparente. No caso de SaJr (2010), portanto, a reescrita da paráfrase, de modo a torná-la mais elucidativa, acarretaria em um ganho maior para o consulente do que a inserção de um exemplo ao verbete.

A reflexão acima exposta indica de que maneira a carência de uma teoria lexicográfica para a compilação de dicionários escolares influencia na qualidade dos produtos finais das obras lexicográficas. Tendo em vista as considerações levantadas, somos levados a crer que a falta de discussão teórica a respeito de paráfrases opacas e paráfrases transparentes parece estar por trás de, pelo menos, três fatos observados nos quadros 2,3 e 4 , a saber, a falta de critérios para a utilização de exemplos, a falta de critérios para a utilização de remissivas para outros verbetes e a falta de critérios para a utilização de remissivas para ilustrações.

$\mathrm{O}$ segundo grupo de informações, que diz respeito às informações que acreditamos serem auxiliares à produção textual, abre espaço para a discussão em torno da função atribuída a um dicionário Tipo 2 . Neste ponto, é necessário estabelecer se uma obra lexicográfica escolar de Tipo 2 se limitaria a auxiliar seus consulentes nas tarefas compreensão textual ou se deveria também auxiliá-los nas tarefas de produção textual. ${ }^{12}$

\footnotetext{
${ }^{12}$ Nossa preocupação em discutir o possível auxílio dos dicionários escolares às tarefas de compreensão e de produção textual advém da grande ênfase dada pelos Parâmetros Curriculares Nacionais a estas duas tarefas. De acordo com as diretrizes fixadas pelos PCNs, que buscam orientara educação básica brasileira, a compreensão e a produção textual constituem atividades a serem desenvolvidas nas crianças de maneira conciliada desde o início da educação básica (PCN, 1997).
} 
Para discutirmos este aspecto da obra lexicográfica, é necessário termos em mente que o dicionário Tipo 2 é, via de regra, um dicionário de orientação semasiológica. A partir da distinção entre onomasiologia e semasiologia, ${ }^{13}$ é possível estabelecer que o dicionário semasiológico cumpre a função de auxiliar o consulente na compreensão linguística, ao passo que o dicionário onomasiológico auxilia o consulente na produção linguística (RIEMER, 2010, p. 49-50). Por seguir os preceitos da semasiologia, ou seja, de tomar como ponto de partida uma palavra individual e buscar o tipo de informação semântica relacionado a esta palavra (GEERAERTS, 2003, p. 84, GEERAERTS, 2010, p. 23), o dicionário semasiológico constitui um instrumento que busca elucidar o significado dos vocábulos arrolados. O dicionário semasiológico, portanto, procura sanar as dúvidas de seus consulentes em relação ao significado das palavras e, por isso, pode ser visto como uma obra lexicográfica que auxilia a compreensão linguística. $O$ dicionário onomasiológico, por outro lado, toma uma perspectiva oposta. Neste tipo de obra, o significado torna-se o ponto de partida da consulta para se chegar às palavras associadas a este significado (GEERAERTS, 2003, p. 84; GEERAERTS, 2010, p. 23), sendo, por isso, uma obra útil à produção linguística. Desta forma, ao informar o coletivo de rapaz, Dijr (2005), embora se apresente como uma obra semasiológica, está cumprindo, também uma função onomasiológica. $\mathrm{O}$ mesmo pode ser dito de SaJr (2010) ao se observar que esta obra fornece a seus consulentes a antonímia de arrumar.

A inserção de um segmento informativo de ordem onomasiológica ao verbete de uma obra lexicográfica semasiológica

\footnotetext{
${ }^{13}$ Nos estudos semânticos, é possível estudar a relação entre um vocábulo e o seu significado a partir de duas perspectivas, a semasiologia e a onomasiologia. Na perspectiva semasiológica, parte-se do significante para se chegar ao significado, ao passo que na perspectiva onomasiológica percorre-se o caminho oposto, ou seja, parte-se do significado para se chegar ao significante (GEERAERTS, 2010, p. 23). Aplicando estas duas perspectivas à prática lexicográfica, podemos falar em dicionários semasiológicos e dicionários onomasiológicos.
} 
não constitui um obstáculo na lexicografia. Pelo contrário, em alguns casos, um segmento onomasiológico pode ser visto como um recurso de grande valor à produção linguística em obras que não foram compiladas essencialmente para este propósito. Um exemplo deste fato pode ser visto na proposta de Farias (2009) para o desenho de um dicionário escolar de língua portuguesa, na qual a autora sugere a inserção de sinônimos na microestrutura de dicionários escolares como um recurso auxiliar à produção linguística dos consulentes. Neste ponto, é necessário frisar que o tipo de dicionário para o qual Farias (2009) apresenta a sua proposta seria o equivalente ao dicionário Tipo 3 segundo a terminologia do MEC, ou seja, um dicionário escolar voltado para terceiro e quarto ciclo do Ensino Fundamental. Nesta etapa da vida escolar, é esperado que os consulentes já apresentem as habilidades linguísticas necessárias para manipularem informações de caráter onomasiológico dentro do verbete tendo em vista o período escolar que estes alunos se encontram. Em um dicionário de Tipo 2, no entanto, estas considerações devem ser reavaliadas, uma vez que ainda não sabemos ao certo se o público-alvo deste tipo de obra teria condições de tirar um bom proveito de informações voltadas para a produção linguística (como o coletivo e a antonímia apresentados pelas obras analisadas).

Mais uma vez, fica evidente que a falta de pesquisas lexicográficas que subjazem a concepção de um dicionário Tipo 2 (no caso, pesquisas que revelem as habilidades linguísticas do público-alvo desta obra) impede que seja estabelecida a necessidade ou não de informações voltadas para a produção textual. Neste caso, diante da falta de um estudo que legitime ou deslegitime a pertinência de informações como a antonímia e o coletivo nos verbetes de dicionários Tipo 2 , fica a critério dos compiladores das obras inserir ou não estas informações ao PCI das obras, sem saber ao certo se as mesmas serão úteis ao consulente.

O terceiro e último grupo de informações diz respeito às informações que auxiliam o consulente em aspectos referente ao uso da língua, seja no esclarecimento sobre dúvidas de pronúncia, 
seja no esclarecimento sobre dúvidas de ortografia. DiJr (2005) e SaJr (2010), por exemplo, ao informarem que o aumentativo de rapaz é rapagão, sugerem a seu consulente que este substantivo sofre uma pequena alteração na sua forma aumentativa (a supressão da letra $z$ e inserção da letra $g$ ), e que a possível forma rapazão seria incorreta. ${ }^{14} \mathrm{O}$ mesmo tipo de recomendação ocorre através da indicação da pronúncia de ruim em AuIl (2008) e Dijr (2005), no qual as obras buscam informar ao leitor que, embora o vocábulo seja comumente pronunciado como uma palavra paroxítona, ele é, segundo a gramática tradicional do português, uma palavra oxítona. Estes dois tipos de informação constituem o que Bugueño Miranda e Farias (2006) convencionaram chamar de informações discriminantes, ou seja, informações que permitem ao leitor tirar proveito sobre o uso ou conhecimento da língua.

Neste momento, cabe retomar a discussão conduzida na seção anterior sobre o valor da presença ou da ausência de um segmento informativo dentro de um verbete. Conforme apresentamos, em um PCI, a ausência de uma informação pode ser tão significativa quanto a presença de outra (DAMIM, 2005). Assim, a supressão de um segmento informativo que indique que o aumentativo de rapaz é rapagão pode levar o consulente a supor que o aumentativo desta palavra ocorre pelo simples acréscimo do sufixo - $\tilde{a} o$ (o que, de acordo com o VOLP, não estaria incorreto). A indicação do aumentativo de rapaz em DiJr (2005) e SaJr (2010), portanto, parece alertar os consulente a respeito de uma formação do aumentativo que, segundo os dicionários, ocorre de maneira irregular. A supressão desta informação por AuIl (2008), por outro lado, parece deixar os consulentes à vontade caso queiram grafar

${ }^{14}$ Curiosamente, indo de encontro ao que é sugerido por Dijr (2005) e SaJr (2010), o Vocabulário Ortográfico da Língua Portuguesa (VOLP) reconhece, em seu corpus, a forma rapazão, o que coloca em discussão a informação oferecida por DiJr (2005) e SaJr (2010). Link para acesso ao VOLP: http://www.academia.org. br/abl/cgi/cgilua.exe/sys/start.htm?sid=23. Acesso em: 23 out. 2013. 
o aumentativo de rapaz da maneira regular. No que concerne este ponto, ou seja, a inserção ou supressão de informações como aumentativos e diminutivos irregulares, soma-se, ainda, mais um fator a ser levado em conta, que é o tipo de consulente ao qual as obras analisadas se dirigem. No momento, pouco sabemos a respeito do tipo de informação que de fato seria funcional para este público em uma obra lexicográfica. Informações como o aumentativo, o diminutivo, o feminino, o plural e a pronúncia de palavras que variam, como rapaz e ruim, parecem ser importantes em um dicionário do tipo geral ou voltado para estudantes do ensino médio. Porém, diante de instrumentos lexicográficos como o dicionário Tipo 2, que tem como público-alvo crianças que cursam o primeiro e o segundo ciclo do ensino fundamental e, por isso, ainda se encontram em fase de familiarização com obras lexicográficas (BRASIL, 2012), permanece a dúvida sobre a funcionalidade deste tipo de informação. Mais uma vez, verificamos que a discrepância entre as obras analisadas advém, essencialmente, da falta de fixação de parâmetros lexicográficos, o que leva os compiladores de dicionários a fazerem escolhas baseados em suas próprias intuições.

\section{Conclusões}

Os quadros 2, 3 e 4 evidenciam que não há, nos dias atuais, uma concepção pré-estabelecida sobre o PCI de dicionários Tipo 2. Além disso, a discussão a respeito das informações contidas nos quadros deixa transparecer que a falta de um modelo para o PCI de obras lexicográficas Tipo 2 repousa, principalmente, na carência de estudos sobre este tipo de dicionários.

A proposta de Bugueño Miranda e Farias (2008, 2009) para a concepção de dicionários escolares estabelece que toda obra lexicográfica deve ser planejada com base em três axiomas básicos: um enquadramento taxonômico, a definição de um perfil de usuário e o reconhecimento da função da obra. Segundo os 
autores, enquanto o enquadramento taxonômico permite que sejam definidos os traços essenciais da obra, o perfil do usuário esclarece o tipo de informação que a obra deve fornecer, ao passo que a função da obra estabelece o papel que o dicionário deve cumprir junto aos seus consulentes. De acordo com Farias (2009), a definição prévia destes três axiomas é condição fundamental para o desenho de uma obra lexicográfica.

A pesquisa lexicográfica brasileira, no entanto, ainda não conta com um estudo que estabeleça os parâmetros pelos quais um dicionário Tipo 2 deve ser compilado. Em outras palavras, ainda não dispomos de informações que reflitam os traços do dicionário Tipo 2 (enquadramento taxonômico), as necessidades de consulta de seus consulentes (perfil do usuário) e as funções que esta obra deve cumprir (função da obra). Desta forma, a compilação de dicionários Tipo 2 ocorre, ainda, de maneira pouco criteriosa. $\mathrm{O}$ principal reflexo desta falta de parâmetros recai nas diferentes configurações que os dicionários Tipo 2 apresentam, ou seja, obras cujos PCIs fornecem os mais variados tipos e quantidades de informação.

O presente trabalho, portanto, surge com o intuito de chamar a atenção para a necessidade de estudos que fixem parâmetros mais objetivos que os atuais para a compilação de dicionários Tipo 2. Conforme nossas análises demonstraram, é necessário se estabelecer quais informações em um verbete de um dicionário Tipo 2 são realmente funcionais para o consulente e quais não seriam pertinentes na microestrutura de uma obra lexicográfica deste porte. 


\section{Referências}

ANTONIOLI, J. Reflexões sobre as políticas de dicionários do governo brasileiro para alunos de alfabetização. Educação E Sociedade, Campinas, v. 32, n. 115, p. 549-563, 2011.

BRANGEL, L. M.; BUGUEÑO MIRANDA, F. V. Avaliação de paráfrases explanatórias de dicionários voltados para alunos em etapas iniciais de alfabetização. In: SIMPÓSIO INTERNACIONAL DE LEXICOGRAFIA E LINGUÍSTICA CONTRASTIVA, I, 3-4 dezembro 2012, Florianópolis. Anais... Florianópolis: Universidade Federal de Santa Catarina, 2012. p. 22-37.

BRASIL. Ministério da Educação. Secretaria da Educação Básica. Com direito à palavra: dicionários em sala de aula. Brasília: Ministério da Educação, Secretaria da Educação Básica, 2012.

BUGUEÑO MIRANDA, F. V. O que é macroestrutura no dicionário de língua? In: ALVES, I. M. A.; ISQUERDO, A. N. (Org.). As ciências do léxico: lexicologia, lexicografia e terminologia. Campo Grande: Humanitas, 2007a. p. 261-272.

BUGUEÑO MIRANDA, F. V. Resenha: Langenscheidt Taschenwörterbuch Deutsch als Fremdsprache. Berlin: Langenscheidt, 2004. Contigentia, Porto Alegre, v. 2, p. 120-123, $2007 \mathrm{~b}$.

BUGUEÑO MIRANDA, F. V.; FARIAS, V. S. Informações discretas e discriminantes no artigo léxico. Cadernos de Tradução, Florianópolis, v. 2, n. 18, p. 115-135, 2006.

BUGUEÑO MIRANDA, F. V.; FARIAS, V. S. Desenho da macroestrutura de um dicionário escolar de língua portuguesa. In: BEVILACQUA, C. R.; HUMBLÉ, Ph.; XATARA, C. M. (Org.). Lexicografia pedagógica: pesquisas e perspectivas. Florianópolis: UFSC/NUT, 2008. p. 129-167.

BUGUEÑO MIRANDA, F. V.; FARIAS, V. S. Panorama crítico dos dicionários escolares brasileiros. Lusorama, Frankfurt am Main, v. 77-78, p. 29-78, 2009. DAMIM, C. P. Parâmetros para uma avaliação do dicionário escolar. 233f. Dissertação (Mestrado em Letras) - Instituto de Letras, UFRGS, Porto Alegre, 2005.

FARIAS, V. S. O exemplo como informação discreta e discriminante em dicionários semasiológicos de língua portuguesa. Alfa, São Paulo, v. 52, n. 1, p. 101-122, 2008. 
FARIAS, V. S. Desenbo de um dicionário escolar de língua portuguesa. 285f. Dissertação (Mestrado em Letras) - Instituto de Letras, UFRGS, Porto Alegre, 2009.

FARIAS, V. S. Aplicação da semântica das condições de verdade à redação das definições nos dicionários semasiológicos. Revista Brasileira de Linguística Aplicada, Belo Horionte, v. 12, n. 1, p. 181-204, 2012.

FORNARI, M. K. Concepção e desenho do front matter do dicionário de falsos amigos espanhol-português. Voz das Letras, Concórdia, n. 9, p. 1-15, 2008.

GEERAERTS, D. Meaning and definition. In: STERKERBURG, P. van. $A$ practical guide to lexicography. Amsterdam: John Benjamins, 2003.

GEERAERTS, D. Theories of lexical semantics. New York: Oxford University Press, 2010.

HAENSCH, G. La lexicografía: de la lingüística teórica a la lexicografia práctica. Madrid: Gredos, 1982.

HARTMANN, R. R. K.; JAMES, G. Dictionary of lexicography. London/ New York: Routledge, 2001.

HAUSMANN, F. J.; WIEGAND, H. E. Component parts and structures of general monolingual dictionaries: a survey. In: HAUSMANN, F. J.; REICHMANN, O.; WIEGAND, H. E.; ZGUSTA, L. (Hrsgn.) Wörterbücher, dictionaries, dictionnaires: ein internationales Handbuch zur Lexikographie. Berlin/New York: Walter de Gruyter, 1989. Band 1, p. 328-360.

LANDAU, S. Dictionaries: the art and craft of lexicography. 2. ed. Cambridge: Cambridge University Press, 2001.

PCN. BRASIL. Ministério da Educação. Parâmetros Curriculares Nacionais: língua portuguesa. Ensino de primeira à quarta série. Brasília: Secretaria da Educação Fundamental, 1997. Disponível em: <http://portal.mec.gov.br/seb/arquivos/pdf/livro02.pdf $>$. Acesso em: 10 set. 2011.

PIRES, J. A. Contribuições para dicionários escolares destinados às séries iniciais. 150f. Dissertação (Mestrado em Letras) - Instituto de Letras, UFRGS, Porto Alegre, 2012. 
RANGEL, E. de O. Dicionários escolares e políticas públicas em educação: a relevância da "proposta lexicográfica". In: CARVALHO, O. L. S.; BAGNO, M. (Orgs.). Dicionários escolares: políticas, formas e usos. São Paulo: Parábola, 2011. p. 37-60.

RIEMER, N. Introducing semantics. New York: Cambridge University Press, 2010.

SELISTRE, I. C. T. Desenho de um dicionário passivo inglês/português para estudantes do ensino médio. 301f. Tese (Doutorado em Letras) - Instituto de Letras, UFRGS, Porto Alegre, 2012.

WELKER, H. A. Dicionários: uma pequena introdução à lexicografia. Brasília: Thesaurus, 2004.

\section{Dicionários}

AuIl 2008. FERREIRA, A. B. de H. Dicionário aurélio ilustrado. 1. ed. Curitiba: Positivo, 2008.

DiJr 2005. MATTOS, G. Dicionário júnior da língua portuguesa. 3. ed. São Paulo: FTD, 2005.

SaJr 2010. SARAIVA JR. Dicionário da língua portuguesa ilustrado. 3.ed. São Paulo: Saraiva, 2010.

Recebido para publicação em 30 de julho de 2013 Aprovado em 7 de setembro de 2013 